\title{
LECCIONES SOBRE LA HEROICIDAD EN LA ILÍADA
}

\section{Lessons on heroism in the Iliad}

Franklin Ibáñez Blancas

Universidad Nacional de San Marcos. fibanezb@unmsm.edu.pe https://orcid.org/0000-0002-1648-6362

\begin{abstract}
RESUMEN
La Ilíada expone los cimientos de la moral occidental. No es un texto simple con una argumentación lineal. Diversas lecciones se obtienen de ella. Algunas enseñanzas pueden parecer contradictorias como el aprecio por la valentía y fuerza sin desmerecer un lugar para la compasión y el perdón. Así el modelo de héroe que nos presenta no corresponde a una máquina de guerra. El artículo explora las diferentes dimensiones de la heroicidad a fin de ilustrar algunas enseñanzas que pueden seguir vigentes en el tiempo actual.
\end{abstract}

\section{Palabras clave:}

Ilíada, Poemas homéricos, heroicidad, ética de la guerra.

\begin{abstract}
The Iliad explains the foundations of western moral. It is not a simple text with a linear argumentation. Several lessons may be obtained from the book. Some teachings can be seen contradictory as the appraisal for courage and force while, at the same time, it does not dismiss the proper place of compassion and forgiveness. Its hero model does not seem to be a machine of war. This paper explores several dimensions of heroism to illustrate some lessons which can be valid in nowadays.
\end{abstract}

\section{Keywords:}

Iliad, Homeric poems, heroism, ethics of war. 
Atribuida al poeta Homero, la magistral obra que analizaremos no ha perdido un ápice de su brillo pese a sus miles de años de antigüedad. La Ilíada constituye un relato fundante de la cultura occidental. Nos sitúa en los cimientos de la moral, no solo occidental, sino también universal. A continuación, extraeremos algunas lecciones que bien siguen vigentes para la ética $y$, particularmente, sobre el concepto de heroicidad, asunto que ha apasionado a sus lectores por siglos.

Podríamos comenzar considerando la Ilíada como un texto de la "prehistoria de la ética". Para comprender tal afirmación, distingamos primariamente dos conceptos cercanos como son ética y moral. En el lenguaje cotidiano en el mundo hispano, se suele utilizar ambos términos como sinónimos, para referirse al conjunto de normas o principios que guían la acción de los grupos hacia lo que se considera justo, correcto o bueno. Sin embargo, en ambientes académicos se les diferencia. Mientras que la moral mantiene el significado apenas descrito -conjunto de normas que orientan el correcto actuar-, la ética se entiende como la reflexión sistemática sobre la moral. Así, la ética es un ejercicio o estudio crítico sobre las normas de conducta. En suma, en el primer sentido ética es equivalente a moral; en el segundo, ética es la disciplina que estudia la moral (Cortina, 2009).

Si bien todas las sociedades han desarrollado una moral o normas para regular su convivencia, no todas ellas han reflexionado sobre su moral de manera consciente. Esto es, no todos los pueblos ejercieron la ética como una disciplina académica. En el mundo occidental ciertamente fueron los griegos los primeros en hacerlo. La historia de la ética, en sentido académico, suele datarse con los textos de Platón, Aristóteles y otros. Sin embargo, conviene notar que estos autores son posteriores por tres centurias a la época de composición de la Ilíada, que se suele situar entre los siglos VIII y VII a.c.

Según dicha terminología, la Ilíada no consiste en una reflexión sistemática, no expresa la disciplina ética en sentido académico. Sin embargo, este célebre relato testimonia ejemplarmente la moral previa a la sistematización crítica y consciente. De hecho, la ética posterior recogerá algunas reflexiones propuestas en la Ilíada. En suma, esta epopeya transmite de manera bella la sabiduría moral que habían adquirido los griegos a través de sus experiencias fundantes y difíciles, como la guerra de Troya. Pese a no ser un texto sistemático o un estudio crítico, la Ilíada está compuesta de historias, metáforas y símbolos que transmiten los cimientos de la moral occidental.

El presente análisis se centra en la ética de la guerra y particularmente en el tema de la heroicidad. ${ }^{1}$ Cabe mencionar que, como a cualquier texto no argumentativo ni lineal, no debemos exigirle coherencia en todas sus partes o elementos. Algunas frases pueden parecer contradictorias entre ellas como sucede con otros textos fundantes como la Biblia o el Mahabarata. Debemos procurar una lectura integral y hermenéutica para hallar los grandes temas y enseñanzas morales subyacentes que perfilan un

1 Para el análisis que sigue, se asume al héroe como suficientemente independiente, autónomo o responsable de sus decisiones. No es infrecuente la intervención de los dioses en el poema. Sin embargo, la mayor parte de críticos contemporáneos concuerda en que tal intervención divina es propia de la época y no resta el carácter propio de agente o responsabilidad de los personajes. Véase el Cap 5 del libro de Rodríguez (2010). 
modelo de héroe. Dicho modelo será por tanto complejo, como lo es la vida humana llena de grises. En suma, pese a que no era el plan de Homero o sus discípulos ofrecer una reflexión sistemática y unívoca, como podríamos esperar hoy, podemos encontrar rasgos fundamentales de un arquetipo de héroe y de humanidad.

Lección 1: El primer enemigo a vencer es el miedo y otras pasiones

La primera enseñanza tiene que ver con la virtud propia del ser humano en tiempo de guerra: la valentía. Siglos después de Homero, Aristóteles explicitará aquello que subyace a la Ilíada, esto es, saber afrontar el miedo. La valentía no es la ausencia del temor, que es una emoción humana que todos experimentamos y de la cual no nos debemos avergonzar. Ignorar el miedo y desconocer las negativas consecuencias de un enfrentamiento significaría osadía o temeridad. Ese es un extremo al que no debemos llegar. El otro extremo, tal vez más fácil de identificar, pero no de evitar, es el ser poseído o dominado por ese sentimiento de temor. Si bien este se produce frecuentemente por un ejercicio de la razón, por ejemplo, entender las consecuencias peligrosas o negativas, para ser superado se requiere "volver a razonar", es decir, reflexionar.

Los héroes de la Ilíada no dejan de experimentar el miedo y la inseguridad. Veamos algunos casos. El príncipe troyano Paris, quien había escapado con Helena, la esposa de Menelao, duda mucho antes de enfrentarse con este. Al divisar a Menelao, Paris huye "como cuando uno retrocede y se aparta al ver una serpiente en las gargantas de un monte; el temblor invade sus miembros, hacia atrás se retira y la palidez apresa sus mejillas" (III, 33-35). Pero su hermano Héctor le reprende duramente (III, 39-57). No es digno de un príncipe escapar así, menos aun si ha sido este el culpable de la guerra -precisamente al fugar con la deslumbrante Helena. Entonces Paris, entra en razón y afronta sus temores. Henchido de valor, propone a Menelao un duelo a muerte por la dama y a fin de acabar con la guerra.

Y aunque Menelao encaró a Paris, más adelante también fue víctima del miedo. Tras asesinar a Patroclo, los troyanos quieren arrebatarle las armas y tomar el cuerpo como trofeo de guerra (XVII). Menelao comprende bien que Patroclo ha muerto al combatir valientemente por los griegos y que todos estos han venido a luchar a la lejana Troya precisamente para vengar la afrenta que significó la fuga o rapto de Helena, su exesposa. Por ello, comprende Menelao que debe proteger el cuerpo de Patroclo del ultraje. No obstante, teme por su vida pues los troyanos son muchos y él está prácticamente solo. Menelao entra en un conflicto: su deber es proteger el cadáver del amigo y aliado, pero sabe que su vida corre grave peligro si resiste al enemigo. Duda y exclama: "! Ay de mí! Si abandono la bella armadura y a Patroclo, que aquí yace por haber buscado mi honra, es de temer que me vitupere el que me vea de los dánaos Igriegos o argivos]" (XVIII 91-93). Sabe bien que sus propias huestes le repudiarán por haberse doblegado ante los rivales. Finalmente, Menelao opta por una salida intermedia. No debe escapar ni resistir solo, ni ceder ante la cobardía ni la temeridad, sino que trae compañeros para que le ayuden en la defensa donde, de todos modos, es posible que también perezca.

El propio Héctor, el mejor de los troyanos, único verdadero rival a la altura de Aquiles fue también víctima 
del pánico. Tras ver la acometida del indomable Aquiles, cual león en venganza por la muerte de su querido Patroclo, Héctor rehúye al combate personal con aquel. "Nada más verlo, Héctor fue presa del temblor y ya no soportó seguir allí, sino que dejó atrás las puertas y echó a huir" (XXII, 136 137). ${ }^{2}$ Líneas arriba notamos que Héctor reprochó a su hermano por una actitud semejante, que ahora lo apresa a él. Sin embargo, se sobrepone. "Ya no huiré de ti,..., como hasta ahora. Tres vueltas he dado a [Troya] la gran ciudad del divino Príamo sin osar resistir tu ataque; más ahora el ánimo me impulsa a detenerme frente a ti, y te apresaré o me apresarás" (XXI, 250-253). Finalmente muere como el mejor y más valiente de los troyanos.

\section{Lección 2: Pervivir más que sobrevivir}

Un elemento fundamental es su presentación del ser humano más allá de los instintos de supervivencia del mundo animal. El hombre es y ya no es una fiera más. En el reino animal, al cual los seres humanos también pertenecemos, lo que interesa es vivir o sobrevivir. Comúnmente se observa en las peleas de animales que el vencido prefiere la huida antes que una muerte grotesca. Pensemos en los leones que se disputan el liderazgo de la manada, el privilegio de ser macho dominante. Al ser derrotado uno prefiere escapar; frente al peligro mayor, también.

Contrariamente, los héroes del mundo homérico se proponen pervivir. A diferencia de los animales que escapan de la pelea cuando la muerte es inminente, la Ilíada nos muestra que la vida humana supera la propia autoconservación. El héroe prefiere morir como un valiente a vivir como un cobarde. No se trata de vivir de cualquier manera o a cualquier precio, sino de forma decente. La vida digna y con honor incluso puede significar la muerte, mas esta no es la última palabra si se asegura la pervivencia o trascendencia en este mundo recibiendo la gloria de la comunidad.

En el duelo al que hicimos referencia en la lección primera, se puede apreciar este conflicto. Paris y Menelao luchan. El último resulta victorioso y próximo a dar muerte a su rival. Paris morirá defendiendo el honor de su pueblo Troya. Pero una diosa, Afrodita lo ayuda a escapar y lo porta donde Helena, la mujer que ama y por la cual ha comenzado la fatídica guerra. Ella lo ama también. Sin embargo, entra en conflicto: quiere a Paris a su lado, pero sabe que su deber no es vivir con ella, sino enfrentar la muerte.

Has vuelto del combate iOjalá hubieras perecido allí doblegado ante el fuerte guerrero que fue mi anterior marido!

Antes te jactabas de ser superior a Menelao, caro a Ares, por tu fuerza, por tus brazos y por tu pica.

Pero ve ahora y desafía a Menelao, caro a Ares, a luchar otra vez en duelo singular. No, yo te aconsejo desistir y evitar con el rubio Menelao el combate en reto de hombre a hombre y la lucha temeraria, no sea que pronto sucumbas bajo su lanza (III, 428 436).

2 Pero ¿por qué huye si está a la altura de Aquiles? Sobre todo, por los libros finales, parece evidente la superioridad de Aquiles. Sin embargo, algunos pasajes muestran, si no su predominio, al menos la gran valía de Héctor. Desalienta Agamenón a su hermano Menelao de enfrentarlo: "Héctor Priamida, ante quien también los demás sienten pavor. El propio Aquiles en la lucha, que otorga gloria a los hombres, se estremece al encararlo, y eso que es mucho mejor que tú" (VII, 112 114). 
Helena quiere una larga vida con Paris, pero reconoce que la vida pierde valor si se vive a escondidas o de rodillas. En esa misma línea, citemos a Aquiles, el mejor de los aqueos. Él encarna bien esta tensión entre una vida larga y el riesgo de una muerte pronta que promete la gloria. "Si sigo aquí luchando en torno de la ciudad de los troyanos, se acabó para mí el regreso, pero tendré gloria inconsumible; en cambio, si llego a mi casa, a mi tierra patria, se acabó para mí la noble gloria, pero mi vida será duradera (IX, 410-417). ${ }^{3}$

Un pasaje especialmente relevante al respecto surge de los labios de Sarpedón, rey de los licios, aliados de los troyanos (XII, 310-328). Sarpedón alienta a su compañero Glauco para atacar juntos la inexpugnable muralla que los griegos han levantado para proteger sus navíos. Es un momento crucial en la batalla pues troyanos y aliados empujaron a los griegos en retroceso casi hasta hacerlos embarcar de regreso a casa. Pero la muralla detiene al contingente a menos que algún valeroso guerrero se arriesgue al asalto. Sarpedón cree que un verdadero rey no merece honor solo por sus apellidos o riquezas, sino precisamente por luchar en primera fila. La exhortación de Sarpedón a Glauco termina con una sentencia contundente: "iVayamos! A uno tributaremos honor o él nos lo tributará" (XII, 328). Queda claro que algún guerrero de cualquiera de los dos bandos perecerá. No obstante, de todos modos, recibirá el kleos o gloria inmortal, la cual no es concedida únicamente a quien triunfa. Los héroes que luchan dignamente viven en la memoria de las comunidades que defendieron o enfrentaron. Aunque muertos, pervivirán en la memoria incluso de los rivales. En suma, "la lucha,..., otorga gloria a los hombres" (VI, 124; XII, 325).

Lección 3: Servidor de la comunidad y leal con los amigos

La idea anterior se conecta con esta nueva lección. La búsqueda y obtención de la gloria relaciona al héroe con su comunidad. El héroe no es un ser autosuficiente, sino interdependiente respecto de su pueblo o comunidad. No lucha para sí, sino para pervivir en la memoria de la comunidad (Lledó 1988). Ser reconocido como justo y bueno implica haber estado a su servicio. La comunidad retribuirá al nuevo ídolo la gloria que le corresponde. Le construirá monumentos, le compondrá cantos y poemas. Le recordará. Honrar la memoria del héroe es una tesis de la Ilíada que ella misma lleva a su cumplimiento. Es un poema épico que rememora las hazañas de los héroes como ejemplos de la comunidad, aunque también existe una mirada crítica de la guerra -que veremos en la lección 6.

Del otro lado, estaría la figura del mercenario, quien no conoce patria ni vínculo alguno con un pueblo, sino que lucha solo en nombre de su interés egoísta. Contrario también al héroe, usualmente encarnado en un rey o noble, está la figura del déspota, una persona que dirige las huestes y su nación hacia su provecho personal. La primera lealtad de este será para con su ambición. Recuérdese que la Ilíada comienza con

3 Es significativo que poco antes en el discurso, de donde se ha extraído la cita, el propio héroe critique esa moral que ahora estaría defendiendo. "Igual lote consiguen el inactivo y el que pelea con denuedo. La misma honra obtienen tanto el cobarde como el valeroso. Igual muere el holgazán que el autor de numerosas hazañas". (IX, 318-320). Como señala Rodríguez (2010), Aquiles podría estar cimentando las bases de una nueva ética donde la vida -que de todos modos no se puede equiparar a la del reino animalimporta más que la muerte. 
la cólera de Aquiles tras haber sido ofendido por el jefe supremo de la alianza griega, el rey Agamenón. Este rey había secuestrado a Criseida, la hija de un sacerdote troyano, el cual suplicó que sea liberada. Agamenón, el captor, solo le concede menosprecio. El sacerdote, mediante plegarias y sacrificios al dios Apolo, consiguió que este castigue con peste y flechas a los griegos. Aquiles exige a Agamenón que devuelva a la joven, pero este condiciona liberarla a cambio de que los griegos le entreguen recompensas equivalentes. El hecho de que su ejército fuese diezmado por la peste, cómo castigo divino por su codicia, no le bastó. Aquiles reprocha a Agamenón, por ser "el más codicioso de todos" $(\mathrm{I}, 122)$ "Rey devorador [de los bienes] del pueblo" (I,230) -además de sinvergüenza $(\mathrm{I}, 158)$. Frente a su avidez, no pondera el bien de sus aliados y súbditos. Por eso Aquiles, lo descalifica: "iAy!! iImbuido de desvergüenza, codicioso! ¿Cómo un aqueo [griegol te va a obedecer, presto a tus palabras, para andar un camino o luchar valerosamente con los hombres?" (I, 150-151). Agamenón responde devolviendo a Criseida y, a la vez, arrebatando Briseida al propio Aquiles -el cual también había raptado a una mujer como trofeo de guerra, mas, al parecer, llegaron a amarse profundamente. Acto seguido Aquiles abandona la guerra. ${ }^{4}$

El héroe no se sirve de unos, sino que sirve a todos. Este argumento se observa también más adelante a propósito del rencor que Aquiles guarda contra Agamenón y de los intentos para que regrese a la lid (Canto IX). Al no pelear
Aquiles, los troyanos están próximos a la victoria. Los jefes griegos procuran persuadirlo para que regrese. Agamenón se arrepiente y le ofrece dones. No queda claro si el arrepentimiento es sincero o solo estratégico al ver cercana la derrota. Pero los amigos, todos valientes y esforzados como él, Odiseo, Fenix, Ayax, le piden que regrese con un argumento sincero y correspondiente a su ética. Le demandan que debe ayudar a los amigos -philoi. Aquiles está en conflicto: desea socorrerles, pero sigue preso de su cólera frente a Agamenón quien precisamente ha violado la amistad o la reciprocidad entre guerreros. Aquiles, al ver próxima la derrota de la coalición griega, autoriza a su escuadrón, los mirmidones, y Patroclo, su mejor amigo, de socorrerla (XVI). El gesto se puede interpretar como un levantamiento "parcial" del enojo para salvar a los amigos. Solo cuando Patroclo es asesinado por los troyanos, depone plenamente la ira y vuelve a luchar junto con los aqueos (Canto XVIII).

Lección 4: Elogiar al rival y enfrentar un verdadero desafío

Para que el héroe alcance la gloria debe enfrentar un verdadero desafío. No existe honor alguno en vencer un reto mínimo. La hazaña consiste en encarar un objetivo que valga la pena, por ejemplo, luchar contra un guerrero magnífico. La actitud contraria, desear que el enemigo sea trivial o inferior, es propia del mediocre. ¿Qué gloria merece un corredor que compite solo o con rivales que francamente están lejos de su nivel? Es destacable el hecho de que la Ilíada llene de adjetivos elocuentes a

4 Pese a esta acción negativa y otras inconductas que podrían citarse, Agamenón es otro héroe importante, al menos dentro de la Ilíada. No se le juzga solo por este hecho, sino también porque venía cumpliendo varios de los ideales de la ética heroica, como se cuenta principalmente en el Canto XI conocido como "la principalía de Agamenón". Sin embargo, existen sombras sobre su grandeza por el lado de la ambición o la crueldad, como se recuerda en otros textos del mundo griego especialmente las tragedias de Euripiedes y Esquilo. 
los luchadores de ambos bandos. Siendo un relato épico escrito por los griegos, no duda en elogiar todo el tiempo a los enemigos, los troyanos. En general se respeta a los guerreros por su temple, no por su nación. Se califica positivamente al enemigo incluso si este resulta odioso. Se le puede llamar malvado o codicioso $\mathrm{y}$, no obstante, reconocer otras dotes o virtudes que posee. Es lo justo.

El relato adorna a los soldados todo el tiempo con adjetivos y metáforas, los cubre de poesía. Un guerrero puede ser catalogado como divino, deiforme, noble, soberbio, magnánimo, o recibir frases compuestas como "valeroso en el grito de guerra", o toda una construcción compleja. Incluso no es extraño contar su historia y parte de sus hazañas previas a este combate, como se suele hacer hasta el día de hoy al resumir brevemente las estadísticas con las que llega un púgil al cuadrilátero. En cambio, en el cine comercial contemporáneo, la imagen de la fortaleza física y los valores bélicos parecen ser suficientes. En el mundo de Homero, no hay prisa por iniciar el combate. Antes bien, es menester presentar con el debido respeto a quienes arriesgan su vida. Quien acostumbrado al cine de acción se acerque a la llíada puede decepcionarse del estilo especialmente si solo está deseoso de ver correr sangre.

La Ilíada glorifica a los combatientes, aun a los rivales. Un buen ejemplo lo encontramos en el interrumpido duelo entre Diomedes, caudillo aqueo, y Glauco, líder de los licios quienes eran aliados de los troyanos (VI, 119-236). Estos dos aguerridos caudillos se encuentran por casualidad uno frente al otro en el campo de batalla. Instantes previos cada uno había observado la magnífica performance en la lucha del otro. Sin conocerse previamente, se aprestan a pelear, pero antes es necesario afirmar la dignidad del enemigo. Comienza Diomedes diciendo a su rival que no sabe quién es y desea saberlo a la vez que ya aprecia lo bien que lucha -"estás muy por delante de todos" (VI, 125). Llega incluso a comparar sus cualidades con algunas propias de los dioses pues lucha como ellos. ¿Será su descendiente? Por último, en su discurso Diomedes da gala de que no es solo un guerrero sino, diríamos hoy, también un hombre culto. El guerrero sabe utilizar las palabras y no solo sus músculos. De hecho, desafía también a su rival en un duelo verbal. Glauco corresponde con otra muestra de respeto y de cultura.
iMagnánimo Tidida! ¿Por qué me preguntas mi linaje?
Como el linaje de las hojas, tal es también el de los hombres
De las hojas, unas tiras a tierra el viento, y otras el bosque hace brotar cuando florece, al llegar la sazón de la primavera.
Así el linaje de los hombres, uno brota y otro se desvanece (145- 149).

Llama magnánimo a su rival. Y le responde con versos ricos en metáforas. Antes de contar su linaje, advierte que es extenso, cual hojas esparcidas por el viento. Como se aprecia, previo al combate con la espada, se lucha con las palabras: a ver quién las emplea mejor. Finalmente, tras haberse enaltecido mutuamente los guerreros, el duelo se canceló porque descubrieron antiguos lazos de hospitalidad que unían a sus familias. De todos modos, el espíritu de glorificar al rival se mantiene. El poeta Homero no escatima elogios para los enemigos troyanos como se nota en las descripciones de Héctor, Eneas, 
Sarpedón, Euforbo entre otros. Tales enaltecimientos también los brinda incluso a los ancianos que ya no pelean como Príamo o Antenor.

Lección 5: Pelear con reglas, seguir un código de ética

No "atacar por la espalda", no agredir con "golpes bajos" son hoy expresiones comunes, cuyo origen literal no está en la Ilíada. Pero la raíz general, limitar las formas de combate, sí se encuentra en la obra. Si bien el guerrero persigue la gloria, no desea obtenerla a cualquier precio. Para ello existen reglas justas o limpias. El compromiso por no hacer trampa, sino obedecer códigos de guerra es patente. Ciertamente algunas conductas manifiestas en la Ilíada nos parecerían abominables desde códigos de combate actuales. Por ejemplo, el IV Convenio de Ginebra (1949) protege a los civiles durante el tiempo de guerra. Establece prohibiciones que claramente no reconocían griegos y troyanos en su época, quienes estaban acostumbrados a la rapiña, incluso al rapto de las mujeres como botín de guerra. De hecho, la Ilíada comienza con la disputa verbal entre Agamenón y Aquiles por el rapto de Criseida, quien es devuelta a regañadientes por Agamenón (Canto I). A su vez este se venga de Aquiles y le roba una mujer, Briseida, que también había sido raptada por Aquiles. La apropiación de mujeres del bando rival era común. Hoy la condenamos.

El punto acá no es si los códigos de ética de la Ilíada pueden mantenerse vigentes. Es obvio que algunos sí y otros no. Lo que interesa rescatar es su novedad para la época. Se puede celebrar que la Ilíada manifieste la existencia de códigos de guerra. El humano no pelea como el animal. No es lucha salvaje, sin normas, donde todo vale. No son solo procedimientos o reglas como las del tipo echar suertes para saber quién arrojará primero la lanza en un duelo (III, 319). Son reglas más de fondo, que obedecen a verdaderos principios. Por ejemplo, justo es que los guerreros valientes sean enterrados por sus deudos. Tras el interrumpido duelo entre Paris y Menelao, las hostilidades se retomaron, pero Héctor nuevamente propone un duelo que termine con la guerra (canto VII). Desafía él mismo a quien de los griegos quiera ser su rival. Ayax, también llamado Ayante, es elegido entre los voluntarios para el combate. Héctor propone que el vencedor pueda quedarse con las armas del vencido pero que respete $\mathrm{y}$ entregue el cuerpo a sus compañeros. Hoy puede parecernos evidente. Pero, insistimos, este antiguo relato recoge una diferencia entre el combate humano y el animal. Respetar el cuerpo, el acuerdo -la paz-, son principios que nos sitúan a gran distancia del combate natural. En el mismo canto VII se relata una tregua luego del duelo, interrumpido por la noche, para que ambos bandos rindan honores a sus muertos.

Por supuesto que esa misma ética de guerra se verá a veces rebasada, pues finalmente los guerreros son humanos, es decir, vacilan entre sus deberes y sus pasiones. Héctor, poseído por su deseo de una próxima y definitiva victoria, violó el código que él mismo proponía al querer apoderarse del cuerpo de su víctima, Patroclo (XVI-XVIII). Más adelante Aquiles, en la escena más esperada de todo el texto, también se deja llevar por la ira en su duelo frente a Héctor, quien volvió a proponer el principio de respetar el cadáver del vencido. (XXII, 247-368). Ante la propuesta de Héctor, Aquiles no vacila en responder enérgicamente: "Igual que no hay juramentos leales 
entre hombres y leones y tampoco existe concordia entre los lobos y los corderos" (262-263). Anuncia abiertamente que enemigos naturales no tendrán paz, que él es superior para el combate físico y que, por estas dos razones más el dolor que provocó la muerte del amigo, combatirá brutalmente, como un león, sin piedad ni ética alguna. ${ }^{5}$ Así sucedió. Luego, su rival herido de muerte suplicó por última vez ser devuelto a sus deudos. Ante la negativa de Aquiles y su aprestamiento para ultrajar el cuerpo, y que sea devorado por "perros y aves de rapiña", Héctor le profetiza una maldición por no observar reglas. "De hierro es el corazón que tienes en las entrañas. Cuídate ahora de que no me convierta en motivo de la cólera de los dioses contra ti el día en que Paris y Febo Apolo te hagan perecer" (357-360). Finalmente sabemos que Aquiles fue muerto por Paris, perdió el favor de los dioses y no alcanzó la vida dichosa como él mismo relataría en su encuentro ya muerto con Ulises (Odisea XI, 488-491).

Lección 6: Amar la gloria y el bien, pero nunca la guerra

El héroe no es un amante de la guerra. Ciertamente Homero muestra reiteradas veces el desenfreno en medio del combate y la avidez de sangre. Pero no los propone como ideales. Desear la gloria no es amar el conflicto, como algunas veces han malinterpretado los espíritus militaristas por milenios. La Ilíada asume la guerra como un estado natural pero no deja de criticarla. No es la meta de la vida. ¿Vale la pena ir a la contienda armada? ¿Es la mejor opción? Es curioso que hasta bien entrado el siglo XX grandes caudillos la admirasen o deseen. Por ejemplo, puede consultarse el libro clásico de Ferro sobre la Primera Guerra Mundial. En el texto "La Gran Guerra", Ferro narra cómo los países entraban a la contienda de manera casi natural y animosa. Para ellos no era un mal necesario, sino una posibilidad de ganar mucho: honores, bienes, tierras, poder, entre otros. Por eso los jefes no hacían esfuerzos reales por solucionar las diferencias de manera pacífica.

En cambio, la Ilíada cuestiona la guerra y contempla alternativas para lograr la paz y contener daños mayores. Por ejemplo, en el Canto III se recuerda una embajada presidida por Odiseo para negociar un resarcimiento a la afrenta sufrida por el rapto de Helena, esposa del rey Menelao. En el mismo canto, se ensaya otra solución: que combatan en duelo singular Menelao y Paris, agraviado y agresor, pues es preferible que uno solo muera y detener la trágica lucha entre ambos pueblos. Se juran y prometen la paz, incluso "la amistad", con rituales. Solo pelearán dos y "el resto, tras sancionar con víctimas [animales sacrificados] amistad y leales juramentos, ojalá habitemos Troya, de fértiles glebas, y ellos regresaran a Argos, pastizal de caballos, y a Acaya, de bellas mujeres" (III 256-258). Lo propio sucede con el combate entre Héctor y Ayante (VII). Terminado este último duelo, se propone otra solución: el pago de una indemnización, o al menos una tregua. Anténor, líder entre los troyanos, propuso originalmente a sus pares devolver a Helena y sus riquezas, pues están embarcados en una sangrienta guerra por su propia culpa: "por traicionar los leales juramentos" (VII, 351-352).

5 "Las convenciones normales de la sociedad humana no aplican más, al menos en cuanto él y Héctor están concernidos. Él confía plenamente en el éxito, y sobre todo está consumido por su deseo de venganza" (Richardson 1993:133). Trad. Propia. 
Por otro lado, el héroe debe hacer espacio a la compasión, al perdón y otros sentimientos nobles no solo para con sus amigos. Ciertamente Aquiles encarna bien la tensión entre aceptar estas emociones humanas y concederlas a sus rivales. Como hemos visto, a veces se muestra firme, acorazado, rudo como al estar enojado con Agamenón pese a que el enfado cuesta caro a los griegos. Sin embargo, acepta la necesidad de perdonar las ofensas y lograr la reconciliación, pues la obstinación es perniciosa, más que inútil, "por muy afligido que estuviera nuestro corazón" (XIX, 57). Es mejor volver a la concordia, admite. "Mas dejemos en paz lo pasado por mucho que nos aflija y dobleguemos, como es fuerza hacer, el ánimo en el pecho. Ahora yo ya depongo mi ira; no debo mantener para siempre un furor obstinado" (XIX, 65-68).

Es significativo que el canto XXIV, centrado en el rescate del cuerpo de Héctor. En tal escena ocupa un lugar central la misericordia que siente Aquiles por Príamo, padre del difunto. El Pélida se ha ensañado con el cadáver de su rival. Los dioses se oponen a tal acto y protegen al cuerpo para que no se corrompa por más que durante días se le arrastre. Príamo acude donde Aquiles y le recuerda un sentimiento moral que une a griegos, troyanos y todos los seres humanos por más enfrentados que estén: la compasión. "Acuérdate de tu padre" (XXIV, 486). La súplica de Príamo es universal. Aquiles es hijo y también padre. Se conmueve, pues el discurso le recuerda que su progenitor, Peleo, es también anciano y sufre por este hijo que lleva diez años alejado de casa. "Respeta a los dioses, Aquiles, y ten compasión de mí por la memoria de tu padre. Yo soy aún más digno de piedad y he osado hacer lo que ningún terrestre mortal hasta ahora: acercar a mi boca la mano del asesino de mi hijo" (503-506). Aquiles llora con Príamo, siente su mismo dolor y acepta su petición. Aunque está lejos de verbalizarlo, intuye las primicias de una noción de humanidad.

\section{Conclusión}

Conviene traer a colación estas reflexiones en contextos donde lamentablemente sigue demasiado presente cierto culto a la guerra y la violencia. Dicha devoción se manifiesta a través de diferentes espacios culturales -desde el cine hasta la información que circula en redes sociales- y costumbres armamentistas a nivel de la sociedad civil-como lamentablemente se aprecia con frecuencia en las calles de Brasil o las escuelas de Estados Unidos- o el gasto militar en los presupuestos de los países - por ejemplo, 1.2\% del PBI para el Perú en el 2018 según el Banco Mundial (2020). Lejos de alimentar tales escenas se encuentra el poema homérico.

Por todo lo visto podríamos resumir estas seis lecciones del siguiente modo. Ante todo, el primer enemigo del héroe no es externo sino interno: las pasiones como el miedo, al cual debe vencer sin caer en osadía. Segundo, la vida a cualquier precio no es la meta última de la existencia: más vale alcanzar la gloria con la muerte digna, si es el caso, que vivir deshonrado. Tercero, la gloria y el honor solo se logran al servir la causa del pueblo o comunidad y ser leal con los camaradas, en vez de buscar solo el interés personal. Cuarto, requisito para alcanzar la gloria es enfrentar un reto verdadero, que esté a la altura de las posibilidades. No se trata de buscar victorias ni rivales fáciles que no dan ningún mérito ni cuestan esfuerzo. Quinto, la lucha se ejecuta con reglas 
o códigos, se reconocen límites. Una victoria con trampas o golpes bajos no produce honor alguno. Sexto, el héroe no destierra de su corazón el anhelo de paz, ni sentimientos o actitudes nobles como la compasión y el perdón.

La imagen del guerrero apenas esbozada puede desalentar a quien se aproxime a la Ilíada buscando un héroe perfecto en virtudes y actos, siempre triunfador y presto al combate. Pero no es el caso. La heroicidad es compleja. Son copiosos los textos donde los propios luchadores añoran la paz, sus familias, sus pueblos. El poema termina no con una escena victoriosa, sino con el funeral de Héctor y el llanto de sus seres queridos, especialmente tres mujeres: Hécuba, Andrómaca y Elena, en otras palabras, una madre, una esposa y una amiga. La comunidad sufre la pérdida del héroe, no un frío asesino, sino un arquetipo de humanidad. Por lo mismo, el poema no es un culto a la guerra, sino su contemplación crítica.

\section{REFERENCIAS BIBLIOGRÁFICAS}

Banco Mundial (2020) Gasto militar (\% del PBI). Recuperado de: https://datos.bancomundial.org/ indicador/MS.MIL.XPND.GD.ZS Consultado 15/08/2020

Cortina, Adela (2009). Ética mínima. Madrid: Técnos. 14ed.

Ferro, Marc (1970). Gran guerra: 1914-1918. Alianza: Madrid.
Homero (1996). Ilíada. Madrid: Gredos. Trad. Emilio Crespo Güemes.

Homero (1993). Odisea. Madrid: Gredos. 2da. Reimp. Trad. José Manuel Pabón.

Lledó, Emilio (1988). El Mundo Homérico. En: Camps, Victoria (ed). Historia de la Ética. Vol 1. Barcelona: Crítica. pp. 15-34

Richardson, Nicholas (1993). The Iliad: A Commentary. Volume VI: books 21-24. Cambridge: Cambridge UP.

Rodríguez, Juan Carlos (2010). El desarme de la cultura. Una lectura de la Ilíada. Madrid: Katz.

Fecha de recepción: 01-04-2020 Fecha de aceptación: 02-05-2020 